\title{
Peculiar Characteristics of Human Mesenchymal Stem Cell Clones Suitable as Tissue Engineering Models
}

\author{
Giulia Silvani ${ }^{1,2 *}$, Daniela Galli1,2, Laura Benedetti ${ }^{1,2}$, Gabriele Ceccarelli ${ }^{1,2}$, Nicola Crosetto ${ }^{4}$, Carla Olivieri ${ }^{3}$, Cesare Danesino ${ }^{3}$ and Maria \\ Gabriella Cusella De Angelis ${ }^{1,2}$
}

${ }^{1}$ Dipartimento di Medicina Sperimentale, University of Pavia, Italy

${ }^{2}$ Centro di Ingegneria Tissutale, University of Pavia, Italy

${ }^{3}$ Department of Hereditary and Human Pathology, University of Pavia, Italy

${ }^{4}$ The van Oudenaarden Systems Biology Lab, Massachusetts Institute of Technology 77 Mass. Av. 68-383 Cambridge, MA 02139, USA

\begin{abstract}
In the last few years' stem cell research contributed to gain a fundamental understanding of how organisms grow and develop and how tissues are maintained throughout adult life. Mesenchymal stem cells (MSC) are selfrenewing, multipotent cells that are present in many adult tissues, such as bone marrow, adipose tissue, trabecular bone and muscle. More recently they have been found also in skin, liver and other tissues. Dermal skin-derived fibroblasts exhibit mesenchymal surface antigen immunophenotype and differentiation capabilities versus the three main mesenchymal tissues (bone, fat and cartilage).

Hereditary Hemorrhagic Telangiectasia affects 1 in 5000 people and leads to abnormal blood vessel formation in skin and mucous membranes. We isolated human dermal fibroblasts from patients with Hereditary Hemorrhagic Telangiectasia $(\mathrm{HHT}$ ) and healthy controls. In order to evaluate future applications of these cells in tissue engineering we compared mesenchymal properties (self-renewal, differentiation potential) of human gingival fibroblasts isolated from healthy and HHT-affected subjects using a combination of phenotypic (flow cytometry), morphologic (senescence), and functional (in vitro differentiation, colony forming unit assay and proliferation assay) criteria. Our results suggest that $\mathrm{HHT}$ cells were ideal candidates for tissue engineering.
\end{abstract}

Keywords: Hereditary Hemorrhagic Telangiectasia; Fibroblastic mesenchymal stem-cell; xCELLigence; tissue engineering

Abbreviations: HHT: Hereditary Hemorrhagic Telangiectasia; FmSCs: Fibroblastic mesenchymal stem-cell-like

\section{Introduction}

Mesenchymal stem cells (MSCs) possess fibroblastic-like morphology, limited but long-term viability, self renewal capability and multilineage potential [1-5]. MSCs originate from fetus mesoderm layer and in the adult reside in a variety of tissue such as: bone marrow stem cells (BMSCs), dermal stem cells, hepatic stem cells, limbal stem cells, adipose derived stem cells and orofacial tissue (adult tooth pulp tissue, periodontal ligament and adult human dental pulp [6-8]; these findings indicate that also adult mammalian mucosa contains tissue derivedstem cells, and that even these fibroblastic MSCs are more plastic than previously appreciated. Several authors could demonstrate by clonal analysis that human dermis-derived fibroblasts have multipotent differentiation potential [9]. Fibroblastic mesenchymal stem-cell-like (FmSCs) present a surface marker expression pattern similar to MSCs, examination of cell size and granularity, as shown by FACS analyses, indicates the homogeneity of the FmSCs population [10].

Oral gingiva which is often resected during general dental treatments and treated as biomedical waste, is an easily obtainable tissue, and cells can be isolated from patients with minimal discomfort [11]. Interestingly, clinical observations and experimental studies consistently indicate that wound healing in the oral mucosa has better outcomes than in the skin, although the healing process and sequence are similar. The oral mucosa is composed of a thin keratinocyte layer with underlying connective tissue, the mayor constituent of this tissue are Gingival fibroblasts (GFs), that are different from skin fibroblasts [12]. These cells adhere and spread well on culture plates, and proliferate without requiring specific culture conditions.
HHT is an autosomal dominant disease characterized by diffuse visceral and muco-cutaneous telangiectases; a person with HHT has a tendency to form blood vessels that lack the capillaries between an artery and a vein; a typical HHT patient has epistaxis, mucocutaneous telangiectases and gastrointestinal bleeding in later life, even though this is only one of the possible scenarios associated with HHT disease [13-14]. This disease is caused either by mutations in endoglin on chromosome 9 (ENG; HHT1) or those of ACVRL1/ALK1 on chromosome 12 (HHT2), respectively [15]. The prevalence of this disease is on average between $10-20 / 100000$, although it is higher in some regions [16-18]. Juvenile polyposis/hereditary hemorrhagic telangiectasia syndrome is caused by mutations in the gene SMAD4 (HHTJP) on chromosome 18; further genes are predicted at loci identified by linkage analyses on chromosomes 5 (HHT3) and 7 (HHT4) [19]. All these genes encode for proteins that are found in the lining of the blood vessels.

We isolated human gingival fibroblasts from biopsies of people suffering from Hereditary Hemorrhagic Telangiectasia (HHT) and from healthy controls.

The objective of this study was to evaluate the mesenchymal

${ }^{*}$ Corresponding author: Giulia Silvani, Dipartimento di Medicina Sperimentale University of Pavia, Italy, Tel:+39-0382987661;Fax: +39-0382422117; Email: ciozi@libero.it

Received May 31, 2011; Accepted July 07, 2011; Published July 09, 2011

Citation: Silvani G, Galli D, Benedetti L, Ceccarelli G, Crosetto N, et al. (2011) Peculiar Characteristics of Human Mesenchymal Stem Cell Clones Suitable as Tissue Engineering Models. J Tissue Sci Eng 2:106. doi:10.4172/21577552.1000106

Copyright: (C) 2011 Silvani G, et al. This is an open-access article distributed under the terms of the Creative Commons Attribution License, which permits unrestricted use, distribution, and reproduction in any medium, provided the original author and source are credited. 
potential of fibroblasts derived from HHT patients in comparison to the ones from normal subjects for possible applications in tissue engineering.

\section{Material and Methods}

\section{Cell isolation and collection}

Biopsies of oral gingiva, from adult patients (6 HHT and 2 healthy controls), were taken during surgical operation after formal consent. To establish cell cultures, tissues were minced with a scalpel without any enzymatic digestion. Fragments were then plated in a $6 \mathrm{~cm}$ culture dish, in growth medium composed by DMEM (Dulbecco's Modified Eagle's medium) supplemented with 10\% FCS (Fetal Calf Serum), 1\% Hepes, 1\% Sodium Pyruvate, 1\% Antibiotics (Penicilline/Streptomicine) and $1 \%$ L-glutamine (all from EuroClone ${ }^{\circledR}$ ). Cells were kept in culture in $5 \% \mathrm{CO}_{2}$ at $37^{\circ} \mathrm{C}$ for one week, then fragments were manually removed and cells were allowed to expand up to $80-90 \%$ confluence.

\section{Cell immunophenotyping}

Around $1.5 \times 10^{5}$ cells were tripsinized to obtain a cell suspension, then incubated 20 minutes in the dark at room temperature with $10 \mu \mathrm{l}$ of fluorochrome-conjugated (FITC or PE) monoclonal antibody (BD Pharmingen and MACS). Cells have been analyzed for haematopoietic (CD34, CD45, CD68, CD14), mesenchymal (CD90, CD105 or endoglin, CD29, CD166), and endothelial surface makers (PECAM [CD31]). After incubation with the specific antibody, cells were washed and analysed with FACS Calibur instrument (Becton Dickinson; BD, Heidelberg, Germany).

\section{Colony-forming unit assays (CFA)}

Cells of both origins (HHT and control) were plated at 1, 2 or 3 cells/well in a 96 multiwell plate in growth medium, and cultured for 14 days, without medium changing. At the end of the culture period, cells were stained with Wright's staining and CFUs were quantified by counting colonies of $>50$ cells.

\section{xCELLigence RT-CES system (Roche TM)}

The RT-CES system is a real time cell analyzer developed by Roche, it is composed by three parts: an electronic sensor analyzer, a device station, and a 96-well e-plate.The e-plate containing tissue culture well is a standard flat-bottom 96-well culture plate, but in the well bottom is incorporated an in circle-on-line sensor electrode arrays. The device station, which is connected with e-plates, is placed in the incubator and connected to the electronic sensor analyzer through electrical cables. The electronic impedance of sensors electrodes is mesured to allow monitoring of changes of cells on the electrodes, this mesure gives back a parameter called cell index. The Cell Index is calculated by the dedicated software as the difference between the mesure of impedance at T0 (media alone) and the one mesured at each time point. As stated by Roche $\mathrm{CI}$ is a dimensionless value that is correlated to cell number and/or viability [20-21]. Under the control of the RT-CES software, experiment data are measured automatically by the sensor analyzer. For this experiment, for each cell type (in dodecuplicate), we seeded 5000 cells $/ \mathrm{cm}^{2}$ (980 cells/well) in $180 \mu$ of DMEM 10\% FCS in E-Plate 96. Cells proliferation was monitored for 1 week, with an impedance measurement every minute. This starting density is the optimal for human mesenchymal cells growth (and differentiation).

\section{$\beta$-galactosidase staining for senescence}

HHT cells at passage 31 (P31) and control cells at passage 27 (P27) were plated at density of 3500 cells $/ \mathrm{cm}^{2}$ in growth medium (DMEM $10 \%$ FCS); after 10 days of culture cells were fixed in $4 \%$ buffered paraformaldehyde. Cells were then stained with the staining solution (4.2 $\mathrm{mM}$ citric acid, $12.5 \mathrm{mM}$ sodium-phosphate, $158 \mathrm{mM}$ sodium chloride, $0.21 \mathrm{mM}$ magnesium chloride, $2.21 \mathrm{mg} / \mathrm{mL}$ potassium ferrocyanide, $1.68 \mathrm{mg} / \mathrm{mL}$ potassium ferricyanide, $1 \mathrm{mg} / \mathrm{mL} \mathrm{X-Gal}$, $\mathrm{pH}$ 6.0) for $24 \mathrm{~h}$ at room temperature as reported by Dimri et al. $\beta$-galactosidase activity (blue cells) at $\mathrm{pH} 6$ is present only in senescent cells and is not found in presenescent, quiescent or immortal cells. $[22,23]$

\section{Detection of telomerase activity}

TRAPEZE $^{\circledR}$ Gel Based Telomerase Detection kit was used to detect and evaluate telomerase activity in HHT and in control cells. This assay is a highly sensitive in vitro assay system for detecting telomerase activity and is based on improved version of the original method described by KIM et al. [24,25]. The assay is a one-buffer, two-enzyme, system utilizing PCR to enhance the sensitivity of telomerase detection in small samples. Cells were lysed and extracted DNA underwent to PCR using specific primers for telomere sequences (provided in the TRAPEZE Kit). For visualization of PCR products we run $25 \mu \mathrm{l}$ of each sample on a $12.5 \%$ non denaturing-PAGE in $0.5 \mathrm{X}$ TBE buffer. This kit also provide, as positive control, a lysate of the tumoral cell line HeLa, because tumoral cells present an high telomerase activity.

\section{Differentiation in vitro}

$5 \times 10^{3}$ cells $/ \mathrm{cm}^{2}$ were seeded in 6 well culture plates. Each culture plate was kept in growth medium until confluence, and then the medium was replaced with specific medium according to the conditions described below to induce osteogenic or adipogenic differentiation. Media were replaced once a week.

For adipogenic differentiation cells were cultured for 3 weeks with differentiative medium composed by the proliferative medium (DMEM $10 \%$ FCS) supplemented with: $0.1 \%$ insulin transferring selenium (ITS), 0.5mM IBTX (3-Isobutyl-1-methylxanthine), $1 \mu \mathrm{M}$ Dexamethasone and $0.2 \mathrm{mM}$ Indomethacin (all supplement from Sigma-Aldrich, Italy). The adipogenic differentiation for HHT and control cells was assessed using Oil Red O stain as an indicator of intracellular lipid accumulation [26].

For osteogenic differentiation cells were cultured for 3 and 4 week with differentiative medium composed by DMEM 10\% FCS supplemented with: $3.5 \mathrm{mM} \beta$-Glycerophosphate and Ascorbic Acid used at a final concentrations of $50 \mu \mathrm{g} / \mathrm{ml}$ (all from Sigma-Aldrich, Italy).

For quantification of matrix mineralization, controls and HHT cells were stained with alizarin Red-S as described previously [27]. After staining, bound dye was solubilized in $10 \mathrm{mM}$ sodium phosphate ( $\mathrm{pH}$ 7.0) containing 10\% cetylpyridinium chloride and quantitated spectrophotometrically at $562 \mathrm{~nm}$, using Nanodrop (Nanodrop ${ }^{\mathrm{TM}}$ Technologies, Wilmington, USA). This quantitation methods is comparable, in accuracy, with the quantitation of hydroxyapatite by binding assay [28].

\section{Real-Time PCR (RT-PCR)}

At the end of the culture period (3 weeks for adipogenic differentiations and 40 days for osteogenic differentiations) we analyzed the expression of human genes involved in adipogenic (ADPF, SREBF1, LEP and PPAR- $\gamma$ ) [29] and osteogenic (ALP, COL I, ON and IBSP) differentiation [30]. Total RNA was extracted using Pure Link 
Citation: Silvani G, Galli D, Benedetti L, Ceccarelli G, Crosetto N, et al. (2011) Peculiar Characteristics of Human Mesenchymal Stem Cell Clones Suitable as Tissue Engineering Models. J Tissue Sci Eng 2:106. doi:10.4172/2157-7552.1000106

Micro-to-Midi Total RNA Purification System (INVITROGEN, USA). Retro transcription was performed using 500 ng of total RNA, using Bio-Rad iScript cDNA Synthesis Kit (Bio-Rad, USA). All our real-time quantitative RT-PCR were performed with Mini-Opticon ${ }^{\circledR}$ Real-Time PCR System (Bio-Rad, Hercules, CA, USA).

\section{Statistical analysis}

Fluorescence activated cell sorting (FACS) analyses, PCR and differentiation assays were performed and analyzed in three independent experiments. Results are expressed as the mean and standard deviation. Differences between HHT and control cells were evaluated using t-test; statistical significance was established at $\mathrm{p}<0.05$. Representative figures are given for stainings.

\section{Results and Discussion}

Gingival derived fibroblasts from HHT and control donors show similar immunophenotype to human bone marrow mesenchymal cells

FACS analysis revealed that HHT and control cells possess the same surface markers expression of mesenchymal stem cells. Cells

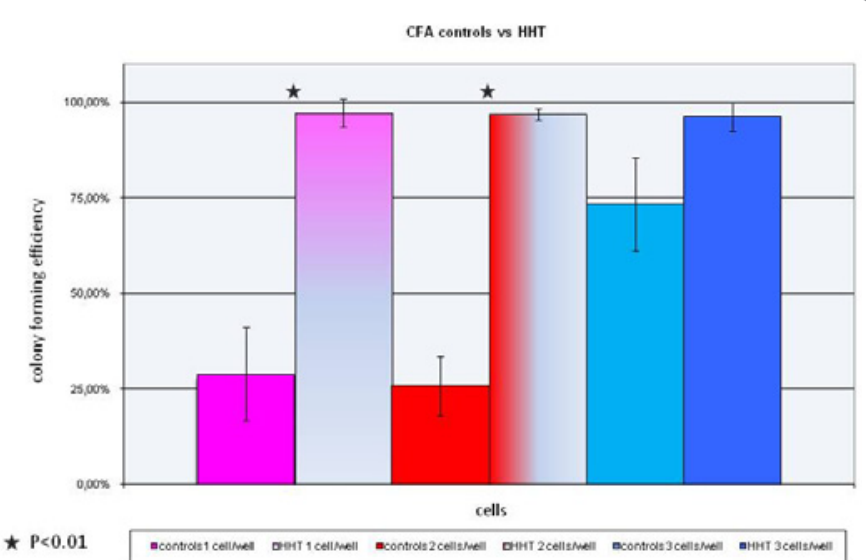

Figure 1: Bar chart of colony forming assay: pink 1 cell/well control cells, pink/grey 1 cell/well HHT cells, red 2 cells/well control cells, red/grey 2 cells/ well HHT cells, light blue 3 cells/well control cells and blue 3 cells/well HHT cells. $\mathrm{P}<0.01$

\section{CTRL vs HHT}

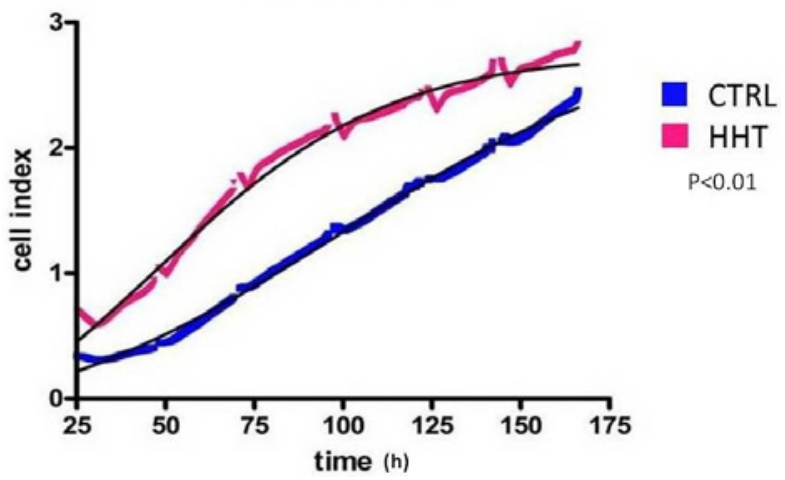

Figure 2: xCELLigence: growth comparison graph between ctrl (mean of two clones, blue line) and HHT cells (means of six clones, pink line), after 1 week of culture. $P<0.01$

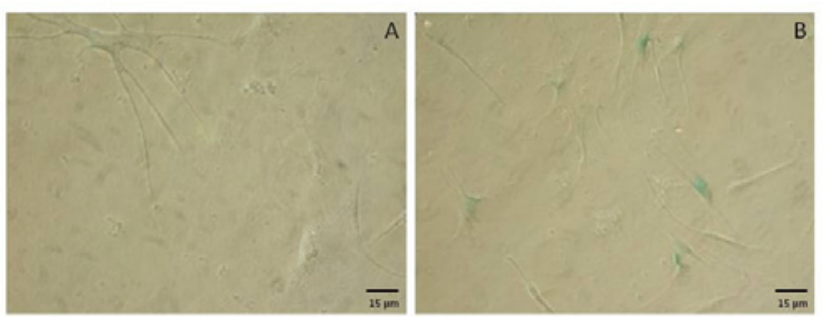

Figure 3: $\beta$-gal staining of HHT cells (A) and control cells (B). Red arrows indicate beta-galactosidase (senescent) positive cells.

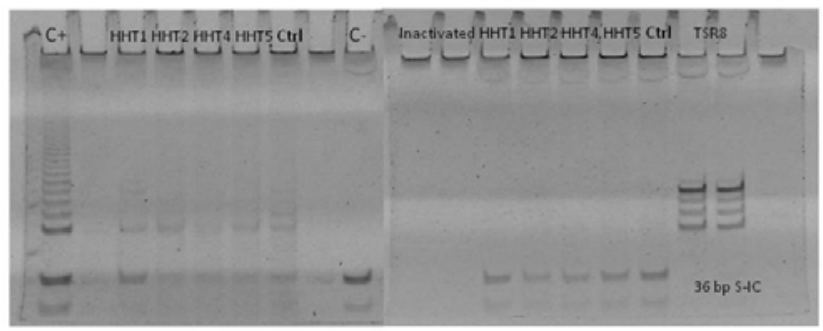

Figure 4: Telomerase activity on 12.5\% PAGE gel: HHT1-4 refers to HHT clones from 4 patients. Only one for each patient is reported but at least three clones from each patient has been analyzed. $\mathrm{C}+$ is the positive control (tumoral cells), ctrl refers to the control cells and $\mathrm{C}$ - is the negative control (water). Bar scale $=15 \mu \mathrm{m}$.

show simultaneous expression of cell surface mesenchymal markers ( $>97 \%$ of cells were positive) as CD13, CD90, CD105 and CD166 with a concomitant absence of haematopoietic and endothelial markers CD45, CD31, CD117 and CD34 ( $<6 \%$ of cells were positive). This expression pattern represents a specific phenotype for cultured MSC.

Examination of cell size and granularity, by FACS analysis, shows the homogeneity of the cells populations analyzed.

\section{HHT gingival fibroblasts show higher colony forming capability than control cells}

When plated at 1 cell/well HHT cells showed a colony forming efficiency of $97.4 \%$, at 2 cells/well of $96.9 \%$ and of $96.3 \%$ when plated at 3 cells/well. Control cells showed a colony forming efficiency of $73.4 \%$ at 1 cell/well, at 2 cells/well of $25.8 \%$ and $28.9 \%$ for 3 cells/well Figure 1. Interestingly, we could detect a significantly higher colony forming capability in HHT cells suggesting a higher proliferation rate of HHT cells with respect to control cells. T.

\section{HHT gingival derived fibroblasts show higher proliferation rate than healthy patients' derived cells}

To test the possibility that HHT cells possess higher proliferation rate than control cells we used the xCELLigence system. The system permits the real time analysis of cell growth and attachment on the basis of mesurament of electronic impedance in each well of the plate. The impedance due to ionic strength of media alone is measured at the beginning of the experiment (T0); the presence of cells alters the impedance because the cells act as an insulator when they attach to the well's bottom. From impedance measurements instrument gives back a Cell Index, which is a relative value indicating how many cells are present in each well. For these types of experiments each measure is done in sample and control cells, thus providing a relative measure and avoiding a standard curve experiment. 
Citation: Silvani G, Galli D, Benedetti L, Ceccarelli G, Crosetto N, et al. (2011) Peculiar Characteristics of Human Mesenchymal Stem Cell Clones Suitable as Tissue Engineering Models. J Tissue Sci Eng 2:106. doi:10.4172/2157-7552.1000106

Page 4 of 7

Figure 2 shows the growth curves of HHTs clones and controls ones in a time period of 1 week. Curves are plotted as average of the CIs measured at each time point in 12 different wells. HHT derived cells, exhibit a proliferation rate higher than those derived from healthy controls.

\section{Control cells show higher senescence than HHT cells}

Senescence is the phenomenon by which normal diploid cells lose their ability to divide. To identify senescent cells we performed the $\beta$-galactosidase staining for senescence. $\beta$-galactosidase associated senescence is microscopically revealed by the presence of a blue, insoluble precipitate within the senescent cell after staining with $\mathrm{x}$-gal. Control cells at passage 27 show a typical blue staining and also an enlarged morphology, Figure 3 B while HHT cells do not appear stained even after 31 passages Figure $3 \mathrm{~A}$.

\section{HHT higher proliferation rate is not associated with tumoral phenotype}

To verify if the higher proliferation rate of HHT cells could be associated with a tumoral phenotype we compared telomerase activity of HHT and control cells using the TRAPeze Telomerase Detection Kit. No PCR amplified products should be visible in the inactivated samples (heat treated), except the 36 bp internal standard control band, while a ladder of PCR products of different weight should be visible in telomerase positive samples (Figure 4). HHT cells show low telomerase activity if compared to positive control cells (HeLa tumoral cell line) and an analogous telomerase activity if compared with cells derived from healthy persons.

\section{HHT cells show higher adipogenic and osteogenic differentiation capabilities than wt cells}

Adipogenic differentiations: To determine if HHT and control cells possess mesenchymal differentiation potential, we cultured them under appropriate conditions using inductive media as described in Materials and Methods.

In HHT cells, fat vesicles could be detected after 3 weeks of culture under inducing conditions Figure 5 C,D. Control cells in the same culture conditions showed no lipidic droplets accumulations Figure 5 A, B.
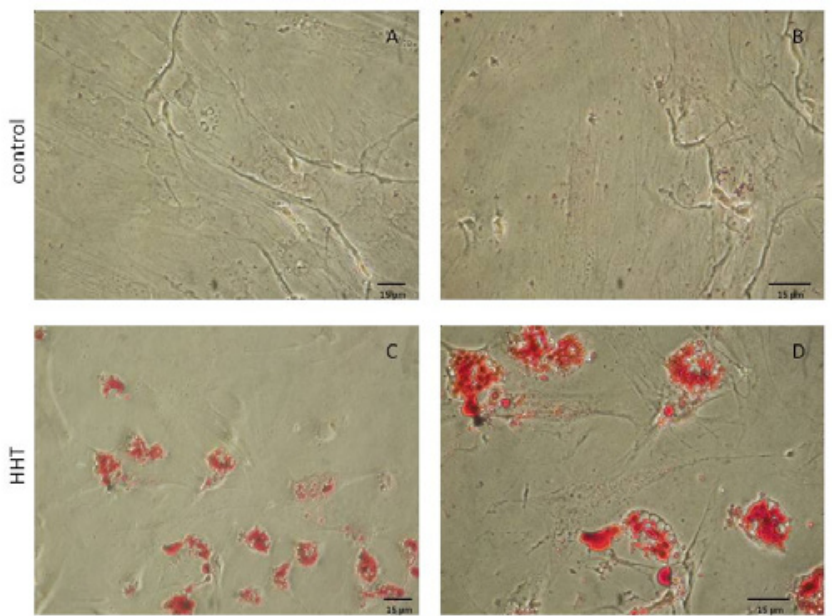

Figure 5: Oil Red staining after 3 week of colture in inductive medium: A e B) control cells, without fat vesicles C e D) $\mathrm{HHT}$ cells with fat vesicles (red droplets). Bar scale $=15 \mu \mathrm{m}$.
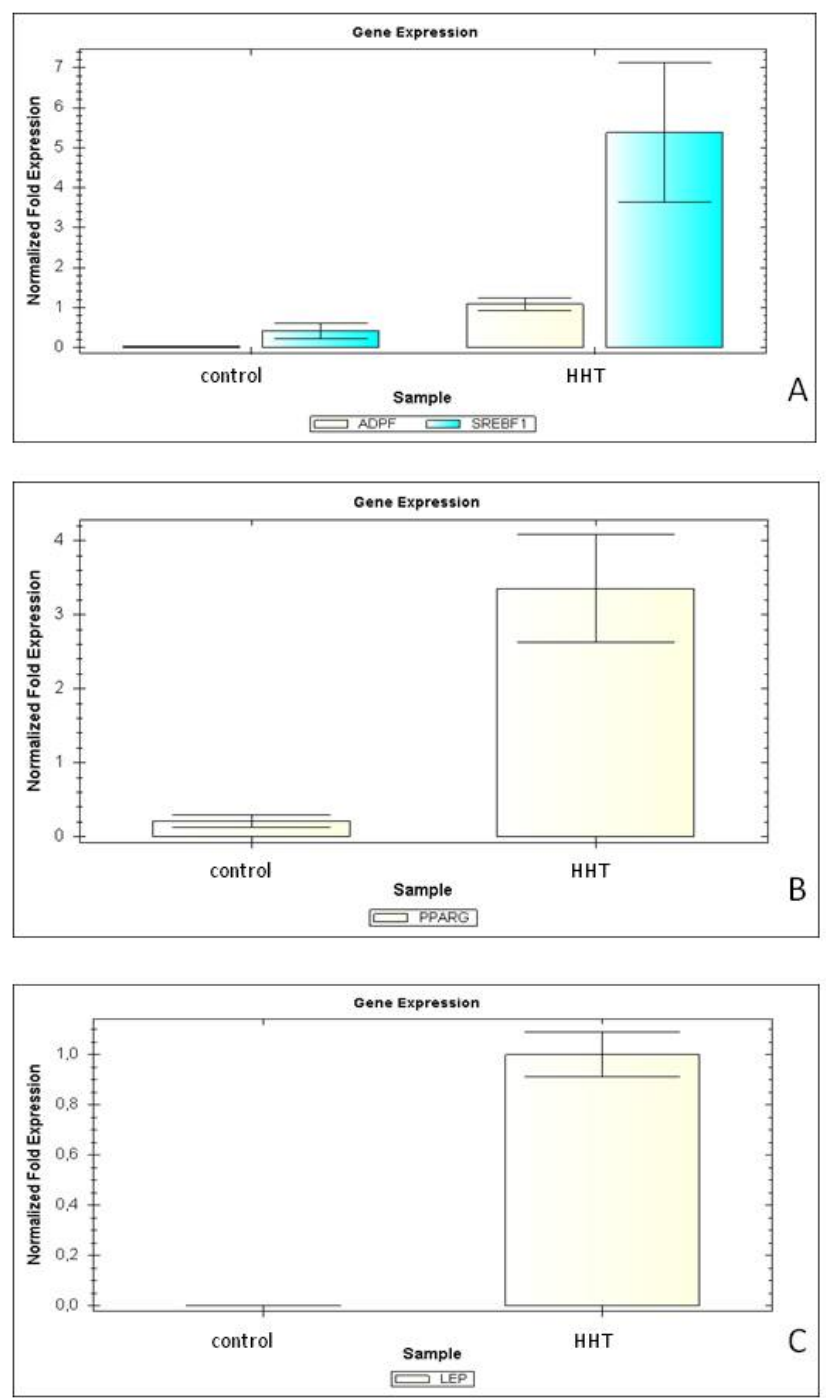

Figure 6: Real time PCR analysis of relative expression of the indicated genes after 3 week in adipogenic medium: A) ADPF and SBREF1, B) PPAR-y, C) LEP (arbitrary units). Gene expressions were normalized to PGK (Phosphoglycerate kinase) gene expression. Each sample was analyzed in triplicate, all the $p$-values were $<0,001$

Gene expression evaluation by Real time PCR of the genes involved in adipogenic differentiation (ADPF, SREBF1, LEP and PPAR- $\gamma$ ), is reported in Figure 6. qPCR results confirm that HHT cells differentiate along the adipogenic lineage after 3 weeks of culture in adipogenic medium, while control cells show expression pattern of undifferentiated cells. In fact there is an up-regulation of ADPF and PPARG- $\gamma$ genes, key factors of adipogenic differentiation; also the expressions of SREBF1 that is involved in sterols synthesis, and leptin that is secreted by white adipocytes are upregulated respect to control.

Osteogenic differentiation: Osteogenic differentiation was analyzed after 21 and 40 days of culture with osteogenic differentiation media (see material and methods). Alizarin Red staining was used to assess calcium deposition: HHT cells showed a marked staining Figure $7 \mathrm{~B}$ respect to the control ones Figure $7 \mathrm{~A}$. Solubilization of bound dye with cetylpyridinium confirmed that HHT cells differentiated better, with the deposition of a greater amount of hydroxyapatite, as shown in Figure 7 C. 
Citation: Silvani G, Galli D, Benedetti L, Ceccarelli G, Crosetto N, et al. (2011) Peculiar Characteristics of Human Mesenchymal Stem Cell Clones Suitable as Tissue Engineering Models. J Tissue Sci Eng 2:106. doi:10.4172/2157-7552.1000106

Page 5 of 7

Morphological results were confirmed By Real time PCR analysis of osteogenic markers gene expression (ALP, IBSP, COL I and ON), Figure 8. After 40 days of culture in osteogenic medium HHT cells show an increase in the expression of all of the genes tested while control cells still have the expression pattern of undifferentiated cells. In particular there is a statistically significant up regulation of genes involved in active bone deposition (ALP) and in matrix mineralization (IBSP), and an over expression of collagen type I and osteocalcin, that are involved in late osteogenesis.

\section{Discussion}

One of the main problems of tissue engineering is the small number of cells and the excessive length of time required to regenerate tissue. For these reasons, researcher try to amplify the number of cells, find new sources of stem cells and reduce the differentiation period needed.

Stem cell therapy in HHT patients has not yet been attempted, moreover there is a paucity of information on HHT bone marrow mesenchymal stem cells due to the difficulty of obtaining them from already severely compromised people.

Therefore with this work we evaluated the mesenchymal potential of skin fibroblasts obtained from patients suffering from hereditary hemorrhagic telangiectasia (HHT) comparing them with those derived from not affected patients for further applications in tissue engineering.

As first step of the characterization we performed FACS analyses that revealed that HHT and control cells possess the same surface
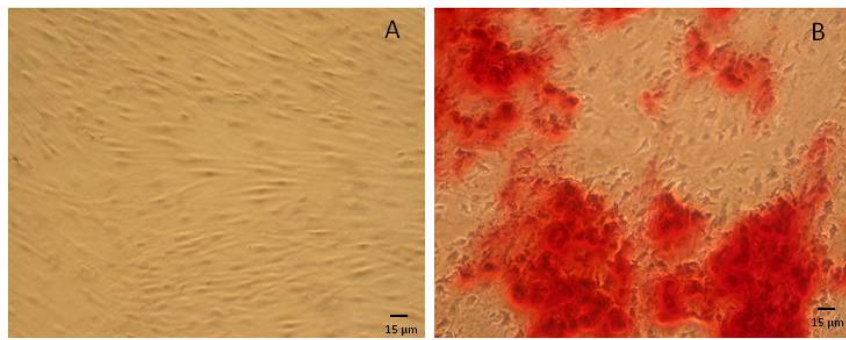

Figure 7: Osteogenic differentiation: Alizarin Red staining A) control cells B) HHT cells. Red precipitates accumulate in correspondence to calcium deposits produced by the cells. Bar scale $=15 \mu \mathrm{m}$.

Alizarin Red S Staining

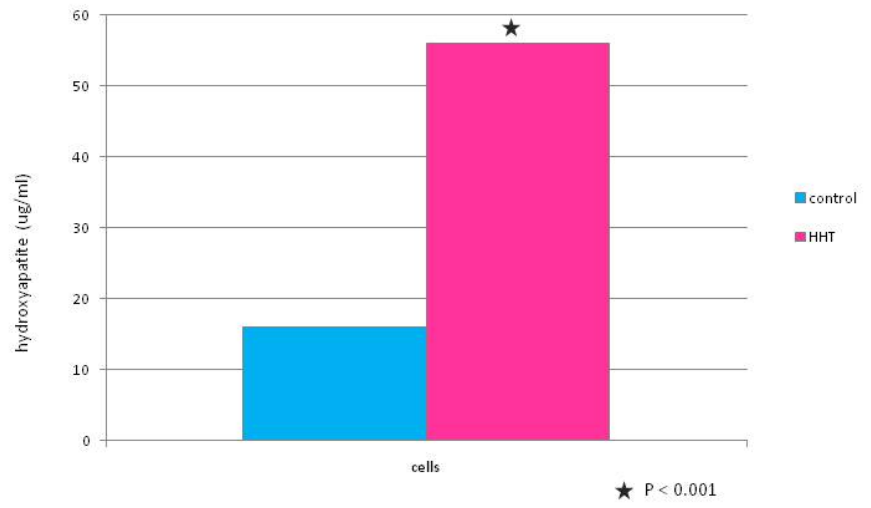

Figure 8: Cetylpyridinium solubilization: comparison of hydroxyapatite levels after cetylpyridinium solubilization in $\mathrm{HHT}$ (pink) and control cells (blue), $\mathrm{P}$ $<0.001$.
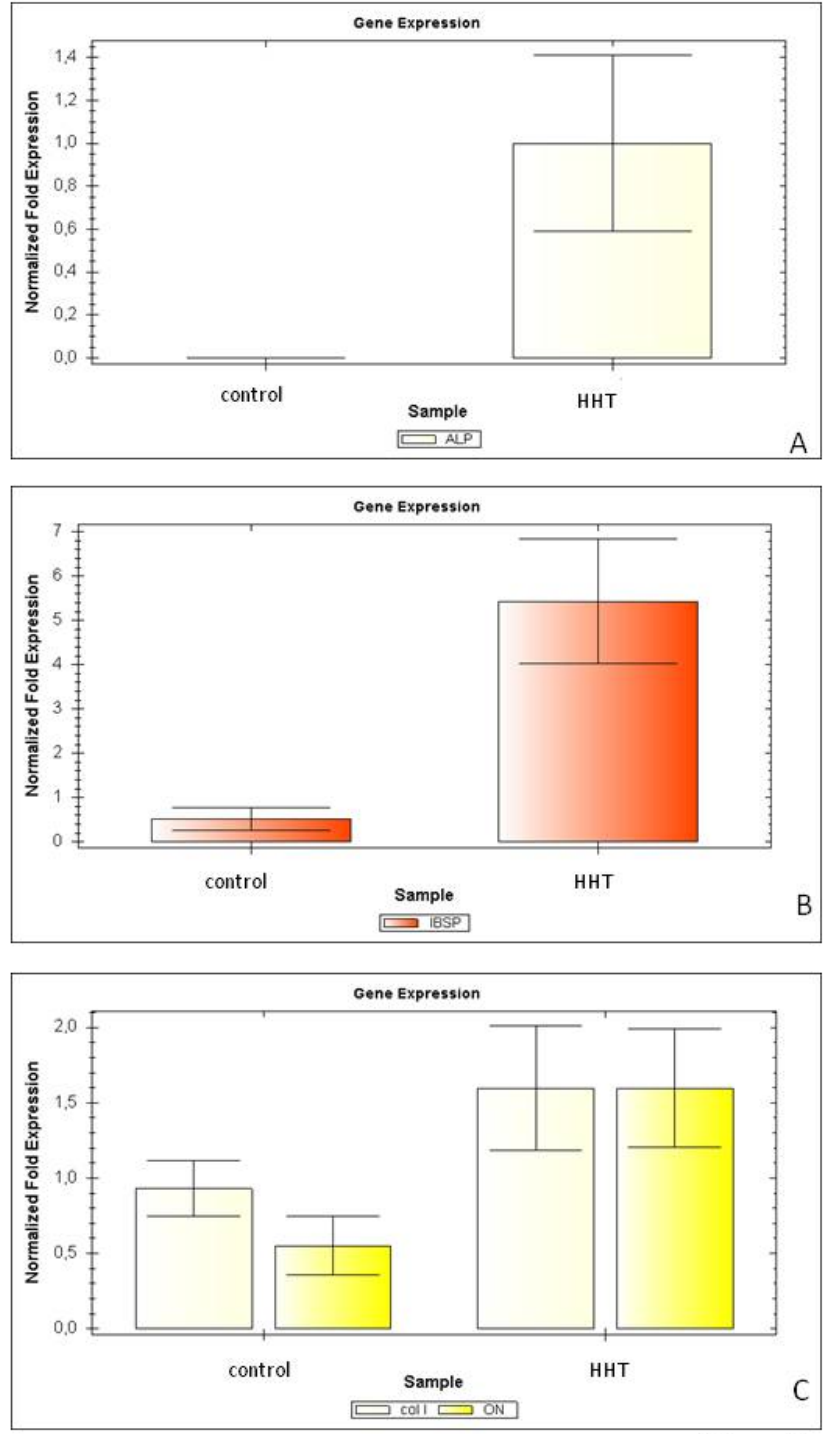

Figure 9: Real time PCR analysis of relative expression of the indicated genes after 40 days in osteogenic medium; a) ALP, b) IBSP, c) COL I and ON (arbitrary units). Gene expressions were normalized to PGK (Phosphoglycerate kinase) gene expression. Each sample was analyzed in triplicate, all the $p$-values were $<0.001$.

markers expression of mesenchymal stem cells. Given this fact we performed a set of experiments trying to assess if there were differences in their "mesenchymal" properties. Firstly we tested their self-renewal potential and the clone forming capability. Interestingly HHT clones showed, respect to the control ones, a higher clonal capability Figure 1 and also a major self-renewal potential as shown by the senescence test Figure 3. Moreover their rate of growth turned out to be higher than the one of control cells as assessed in 1 week experiments performed with the xCELLigence system by Roche Figure 2. Analysis of telomerase activity showed that HHT cells possess low telomerase activity if compared to positive control cells (HeLa tumoral cells) and an analogous telomerase activity if compared with cells derived from healthy persons.

Lastly we determined if HHT and control cells possessed mesenchymal differentiation potential, culturing them under 
Citation: Silvani G, Galli D, Benedetti L, Ceccarelli G, Crosetto N, et al. (2011) Peculiar Characteristics of Human Mesenchymal Stem Cell Clones Suitable as Tissue Engineering Models. J Tissue Sci Eng 2:106. doi:10.4172/2157-7552.1000106

Page 6 of 7

\begin{tabular}{|c|c|c|c|}
\hline Primer & Sequence & Product size & Annealing temperature \\
\hline PGK & $\begin{array}{l}\text { For: 5' TGCCTGTTGACTTTGTCACTGCTG 3' } \\
\text { Rev: 5' AGCCTCAGCATACTTCTTGCTGCT 3' }\end{array}$ & 112 bp & $60^{\circ} \mathrm{C}$ \\
\hline ADPF & $\begin{array}{l}\text { For: 5' AGCCCCTTACAGGCATAGGT 3' } \\
\text { Rev: 5' GTGAGATGGCAGAGAACGGT 3' }\end{array}$ & $121 \mathrm{bp}$ & $60^{\circ} \mathrm{C}$ \\
\hline LEP & $\begin{array}{l}\text { For: 5' GTAGGAATCGCAGCGCC 3' } \\
\text { Rev: 3' GGGCACACGTTGGACATAGA 3' }\end{array}$ & $125 \mathrm{bp}$ & $60^{\circ} \mathrm{C}$ \\
\hline PPAR-y & $\begin{array}{l}\text { For: 5' CCAGAAAGCCATTCCTTCAC 3' } \\
\text { Rev: 3' CGGAGCTGATCCCAAAGTT 3' }\end{array}$ & 109 bp & $60^{\circ} \mathrm{C}$ \\
\hline SREBF1 & $\begin{array}{l}\text { For: 5'CAAATAGGCCAGGGAAGTCA 3' } \\
\text { Rev: 5'ACGAGCCACCCTTCAGC 3' }\end{array}$ & 138 bp & $60^{\circ} \mathrm{C}$ \\
\hline ALP & $\begin{array}{l}\text { For: 5' CTA TCC TGG CTC CGT GTC C 3' } \\
\text { Rev: 5' AGC CCA GAG ATG CAA TCG 3' }\end{array}$ & 138 bp & $60^{\circ} \mathrm{C}$ \\
\hline COLI & $\begin{array}{l}\text { For: 5' CAT GTT CAG CTT TGT GGA CC 3' } \\
\text { Rev: 5' TTC TGT ACG CAG GTG ATT GG 3' }\end{array}$ & $107 \mathrm{bp}$ & $60^{\circ} \mathrm{C}$ \\
\hline IBSP & $\begin{array}{l}\text { For: 5' GGG CAG TAG TGA CTC ATC CG 3' } \\
\text { Rev: 5' TCA GCC TCA GAG TCT TCA TCT TC 3' }\end{array}$ & $90 \mathrm{bp}$ & $60^{\circ} \mathrm{C}$ \\
\hline ON & $\begin{array}{l}\text { For: 5' GAGAAAGAAGATCCAGGCCC 3' } \\
\text { Rev: 5' GCCTGTCTCAAACCCCTCC 3' }\end{array}$ & $126 \mathrm{bp}$ & $60^{\circ} \mathrm{C}$ \\
\hline
\end{tabular}

Table 1: Primers list. List of the primers used in real-time quantitative RT-PCR.

appropriate conditions using adipogenic and osteogenic inductive media. Once again the response of the clones derived from HHT patients is stronger in both cases. When cultured in adipogenic medium the HHT cells up regulate the expression of all the genes tested along the adipogenic pathway Figure 6. Results of gene expression analysis were confirmed by Oil Red staining. Control cells, after 3 weeks in adipogenic medium, showed no lipidic droplets accumulations Figure $5 \mathrm{~A}, \mathrm{~B}$, while in HHT cells, fat vesicles could be detected in the same culture conditions Figure 5 C, D. Data obtained from molecular biology analysis demonstrate that HHT cells possess the property to differentiate along the osteogenic lineage after 40 days of culture in osteogenic medium, with an up regulation of ALP and IBSP Figure 8, genes involved in bone deposition and matrix mineralization; control cells show instead the molecular pattern of undifferentiated cells. Alizarin Red staining confirmed molecular biology results, in fact HHT cells depose a greater amount of hydroxyapatite Figure 7 A B C. Using a combination of phenotypic (flow cytometry), morphologic (senescence), and functional (colony forming unit assay, proliferation assay and differentiation) criteria, this work could demonstrate that HHT cells fulfils the main characteristics of MSCs [31]. These cells express homogenously all MSC-related surface antigens whereas the expression of $\mathrm{CD}$-proteins typical for hematopoietic cells remained undetectable, they differentiate along the adipogenic and osteogenic cell lineages, furthermore they are highly clonogenic (colony forming efficiency about 97\%), show a high proliferation potential, and an enhanced capacity of self renewal along with a major stability within passages even when cryopreserved or sub cultured.

HHT cells can be isolated easily, their expansion in culture is very convenient (in vitro expansion without growth factor), thus making them ideal candidates for tissue engineering. HHT cells also represent a dynamic system suitable to the identification of new molecular targets and the development of novel drugs, which can be tested in vitro for safety or to predict or anticipate potential toxicity in humans.

\section{Acknowledgments}

This project is partially found by FIRB (2005 RBIP06FH7J 001) and by Cariplo Project 2006.

\section{References}

1. Caplan Al (1991) Mesenchymal stem cells. J Orthop Res. 9(5): 641-50.
2. Prockop DJ, Sekiya I, and Colter DC (2001) Isolation and characterization of rapidly self-renewing stem cells from cultures of human marrow stromal cells. Cytotherapy 3: 393-396.

3. Verfaillie CM (2002) Adult stem cells: assessing the case for pluripotency. Trends Cell Biol, 12: 502-508.

4. Nadig RR (2009) Stem cell therapy - Hype or hope? A review. J Conserv Dent. Oct; $12: 131-138$

5. Bianco P, Robey PG, Simmons PJ (2008) Mesenchymal stem cells: revisiting history, concepts, and assays. Cell Stem Cell 2: 313-319.

6. Gronthos S, Mankani M, Brahim J, Robey PG, Shi S (2002) Postnatal human dental pulp stem cells (DPSCs) in vitro and in vivo. Proc Natl Acad Sci USA 97: $13625-13630$

7. Aust L, Devlin B, Foster SJ, Halvorsen YD, Hicok K, et al. (2004) Yield of human adipose-derived adult stem cells from liposuction aspirates. Cytotherapy 6 : 7-14.

8. Guilak F, Lott KE, Awad HA, Cao Q, Hicok KC, et a.l (2006) Clonal analysis of the differentiation potential of human adipose-derived adult stem cells. J Cell Physiol 206: 229-237.

9. Lorenz K, Sicker M, Schmelzer E, Rupf T, Salvetter J, et al. (2008) Multilineage differentiation potential of human dermal skin-derived fibroblast. Exp Dermato 17: 925-932.

10. Barry FP, Boynton RE, Haynesworth S, Murphy JM, Zaia J (1999) The monoclonal antibody $\mathrm{SH}-2$, raised against human mesenchymal stem cells, recognizes an epitope on endoglin (CD105). Biochem. Biophys. Res Commun 265: 134-139

11. Lysy PA, Smets F, Sibille C, Najimi M, Sokal EM (2007) Human skin fibroblasts: from mesodermal to hepatocyte-like differentiation. Hepatology. 46: 15741585

12. Egusa H, Okita K, Kayashima H, Yu G, Fukuyasu S, et al. (2010) Gingival Fibroblasts as a Promising Source of Induced Pluripotent Stem Cells. PLoS ONE 5: e12743.

13. Snyder LH, Doan CA (1944) Clinical and experimental studies in human inheritance: is the homozygous form of multiple telangiectasia lethal? $\mathrm{J} \mathrm{Lab}$ Clin Med; 29: 1211-1216.

14. Shovlin CL, Letarte M (1999) Hereditary hemorrhagic telangiectasia and pulmonary arteriovenous malformations: issues in clinical management and review of pathogenic mechanisms. Thorax. 54:714-729.

15. Lenato GM, Guanti G (2006) Hereditary hemorrhagic telangiectasia (HHT) genetic and molecular aspects. Curr Pharm Des 12: 1173-1193.

16. Plauchu H, Bideau A (1984) Épidémiologie et constitution d'un registre de population à propos d'une concentration géographique d'une maladie héréditaire rare. Population 4-5:765-786. 
Citation: Silvani G, Galli D, Benedetti L, Ceccarelli G, Crosetto N, et al. (2011) Peculiar Characteristics of Human Mesenchymal Stem Cell Clones Suitable as Tissue Engineering Models. J Tissue Sci Eng 2:106. doi:10.4172/2157-7552.1000106

17. Kjeldsen AD, Vase P, Green A (1999) Hereditary hemorrhagic telangiectasia: a population-based study of prevalence and mortality in Danish patients. J Intern Med 245:31-39.

18. Lesca G, Genin E, Blachier C, Olivieri C, Coulet F, et al. (2008) Hereditary hemorrhagic telangiectasia: evidence for regional founder effects of ACVRL1 mutations in French and Italian patients. Eur J Hum Genet 16: 742-749.

19. Shovlin CL, Hughes JM, Tuddenham EG, Temperley I, Perembelon YF, et al (1994) A gene for hereditary hemorrhagic telangiectasia maps to chromosome 9q3. Nat Genet.6:205-209.

20. Roche Diagnostic GmbH. (2008) Instruction of the RTCA SP Instrument Operator's Manual, A. Acea Bioscences, Inc. pp 14-16

21. Atienza JM, Yu N, Wang X, Xu X, Abassi Y (2006) Label-free and realtime cellbased kinase assay for screening selective and potent receptor tyrosine kinase inhibitors using microelectronic sensor array. J Biomol Screen 11: 634-643.

22. Bruder SP, Jaiswal N, Haynesworth SE (1997) Growth kinetics, self-renewal, and the osteogenic potential of purified human mesenchymal stem cells during extensive subcultivation and following cryopreservation. J Cell Biochem 64: 278-294.

23. Dimri GP, Lee X, Basile G, Acosta M, Scott G,et al (1995) A biomarker that identifies senescent human cells in culture and in aging skin in vivo. Proc NatiAcadSCi USA 92: 9363-9367.

24. Kim NW, Piatyszek MA, Prowse KR, Harley CB, West MD, et al. (1994) Specific association of human telomerase activity with immortal cells and cancer. Science 266: 2011-2015

25. Van der Loo B, Fenton M.J, Erusalimsky JD (1998) Cytochemical detection of a senescence-associated beta-galactosidase in endothelial and smooth muscle cells from human and rabbit blood vessels. Exp Cell Res 241: 309-315.

26. Preece A (1972) A Manual for Histologic Technicians. Boston, MA: Little, Brown and $\mathrm{Co}$

27. Stanford CM, Jacobson PA, Eanes ED, Lembke LA, Midura RJ (1995) Rapidly forming apatitic mineral in an osteoblastic cell line (UMR 106-01 BSP). J Biol Chem 270: 9420-9428.

28. Schiller PC, D'Ippolito G, Roos BA, Howard GA (1999) Anabolic or catabolic responses of MC3T3-E1 osteoblastic cells to parathyroid hormone depend on time and duration of treatment. J Bone Miner Res 14: 1504-1512.

29. Li A, Simmons PJ, Kaur P (1998) Identification and isolation of candidate human keratinocyte stem cells based on cell surface phenotype Proc Natl Acad Sci USA 95: 3902-3927

30. Poliard A, Ronzière MC, Freyria AM, Lamblin D, Herbage D, et al. (1999) Lineage-dependent collagen expression and assembly during osteogenic or chondrogenic differentiation of a mesoblastic cell line. Exp Cell Res 253: 385 395

31. Yokoyama C, Wang X, Briggs M.R, Admon A, Wu J, et al. (1993) SREBP-1 a basic-helix-loop-helix-leucine zipper protein that controls transcription of the low density lipoprotein receptor gene. Cell 75: 187-197. 